\title{
ANTHROPOMETRIC PROFILE OF CHILDREN WITH CYANOTIC AND NONCYANOTIC CONGENITAL HEART DISEASE
}

\author{
Mahrus Abdur Rahman ${ }^{1 *}$, I Ketut Alit Utamayasa ${ }^{1}$, Taufiq Hidayat ${ }^{1}$, Roedi Irawan ${ }^{1}$, Rina Elizabeth ${ }^{1}$ \\ ${ }^{1}$ Department of Child Health, Faculty of Medicine, Universitas Airlangga, Surabaya, Indonesia \\ *E-mail: mahrus_rahman@yahoo.com
}

\begin{abstract}
Impaired nutritional status is a frequent complication of congenital heart disease (CHD). Non cyanotic congenital heart disease (NC-CHD) have problem with lung overflow and heart failure. Consequences of Cyanotic congenital heart disease (C-CHD) are decrease pulmonary blood flow and prolong hypoxia. These conditions can have effect on nutritional status and outcome of surgery. This study aimed to compare anthropometric profiles of children with C-CHD and NC-CHD. Cross-sectional study conducted in 66 children, age 3 months until 5 years old who met inclusion criteria in Pediatric Cardiology Outpatient Unit Dr. Soetomo Hospital Surabaya in November 2012. A total of 66 children, consisted of 26 children with C-CHD and 40 children NC-CHD included in study. We measure weight, length/height, head circumference, upper arm circumference, and skin fold thickness. We used Chi Square test for statistical analysis with Confidence Interval 95\%. Mean age of both groups was $27.82 \pm 16.63$ months. Majority of NC-CHD was Ventricular Septal Defect (28.6\%) and C-CHD was Tetralogy of Fallot (21.4\%). There were no significant difference from weight for age, length for age weight for length, head circumference for age, mid upper arm circumference for age, mid upper arm circumference for age, and skin fold thickness for age between children with C-CHD and NC-CHD $(\mathrm{p}=0.80 ; 0.98 ; 0.540 .29 ; 0.80 ; 0.53$ respectively). There were no difference in anthropometric profiles among children with cyanotic congenital heart disease and non-cyanotic congenital heart disease in this study.
\end{abstract}

Keywords: anthropometric, children, non-cyanotic, cyanotic, congenital heart disease

\section{INTRODUCTION}

Impaired nutritional status is a complication that often occurred in children with congenital heart disease (CHD) (Kumar\& Tynan 2005). Malnutrition is very common in children with CHD and is predicted by presence of congestive heart failure, older age at correction and lower growth potential. Heart surgery in children in developing countries is often delayed as a result of limited economic, tools and human resources. While long time waiting for surgery, complications arise. (Kumar \& Tynan 2005). These conditions cause high incidence of nutritional status impairment (Vaidyanathan et al., 2002). Contrary corrective intervention significantly improves nutritional status on short term follow-up (Vaidayanathan et al., 2008). Prevalence of underweight in noncyanotic CHD was greater than in cyanotic CHD $(83,16 \%$ vs $72 \%)$. Prevalence of stunting in noncyanotic CHD was greater than in cyanotic CHD (60,39\% vs $48 \%$ ) (Rubia et al., 2018).

Children with congenital heart disease are at increased risk for poor growth. Several factors may play a role in poor growth including feeding difficulties, increased caloric requirements, and the effects of cardiac lesion on growth regulation. Children with CHD experience early simultaneous decreases in growth trajectory across weight, length, and head circumference. The simultaneous decrease suggests a role for altered growth regulation in children with CHD (Daymont et al., 2013). Children with CHD develop severe undernutrition and growth failure. The significant contributing factors are mean age at presentation and age appropriate dietary adequacy. However pulmonary hypertension appear to be the most important factor, and cyanotic patients with pulmonary hypertension are the most severely affected (Arodiwe et al., 2015).

Malnutrition is a very common problem in children with symptomatic CHD and predicted by the presence of low hemoglobin level, low arterial oxygen saturation, heart failure, poor dietary history, and pulmonary hypertension (Hassan et al., 2015). The purpose of this study is to analyze the difference anthropometric profile in children 
with cyanotic and non cyanotic congenital heart disease.

\section{METHODS}

\section{Study Design}

A cross-sectional study was conducted in 66 children with C-CHD and NC-CHD in the Outpatient Clinic of Division of Cardiology Child Health Department, Dr.Soetomo Hospital, Surabaya in November 2012. Sample size was calculated. Subject were collected by consecutive sampling. Diagnosis of C-CHD and NC-CHD were based on clinical condition and echocardiography examinations. Subjects were aged 3 months until 5 years old who met inclusion and exclusion criteria.

\section{Inclusion and Exclusion Criteria}

Inclusion criteria were patients with cyanotic and non-cyanotic CHD with moderate and severe lession, aged 3 months to 5 years old, never did operation before and parents or guardian signed inform consent. Patients with another congenital syndrome (Down syndrome, turner syndrome and other trisomy), chronic disease (TB, malabsorption), and neurological abnormalities (cerebral palsy, hydrocephalus) were excluded.

\section{Variable Measurement}

Body weight were measured using digital scale. Baby body length was measured with baby lay down and stretch measuring tape from top of the head to bottom of the heel. Children body height was measured with stand back to the wall in an upright position, barefoot, hands hanging freely, and eyes looking straight ahead. The measurement results were in centimeter. Weight and length/ height subjects were measured during outpatient clinic time. Measuring the head circumference by placing a tape measurement around the head through glabella on the forehead and the back of the head (occipital protuberentia). The tape was in a tight state. The measurement results were expressed in centimeters. Head circumference measurements was to know reduction in head dimensions in children performed who are suffering from CHD indicates the reduction in growth of brain (Safikhani et.al., 2007).

Measurement of skin fold thickness (SFT) using skinfold caliper. Measurement were made by pinching the skin apart from the muscles and then the skin folds were measured by caliper. The measurement results were expressed in millimeters. Z-scores (standard deviation scores) is the best system for analysis and presentation of anthropometric data. In this database, weightfor-height, height-for-age, and weight-for-age are interpreted by using the Z-score classification system. $Z$ score between $-2 \mathrm{SD}$ to $+2 \mathrm{SD}$ classified as normal nutrition. $\mathrm{Z}$-score $<-2 \mathrm{SD}=$ low $\mathrm{W} / \mathrm{A}=$ low $\mathrm{H} / \mathrm{A}=$ low $\mathrm{W} / \mathrm{H}$ classified as moderate to severe undernutrition. Weight-for-height Z-score $<-3 \mathrm{SD}$ classified as severe undernutrition dan $>+2 \mathrm{SD}$ classified as overweight (WHO 2006).

\section{Statistical Analysis}

Statistical analysis used was descriptive methods with calculating mean, standard deviation, and analytic methods Chi square test for the difference between the 2 groups.

\section{Ethical Clearance}

Ethical clearance was issued by the ethics committee of health research, Dr. Soetomo Hospital, Surabaya, Indonesia (No. 1829/105/ $\mathrm{XI} / 2019$.)

\section{RESULTS AND DISCUSSION}

A total of 66 children, consisted of 26 children with C-CHD and $40 \mathrm{NC}-\mathrm{CHD}$. The characteristic of the groups were not significantly different. The mean age of both groups was $27.82 \pm 16.63$ months old. There was no difference in sex distribution intra and inter group. Male and female ratio in C-CHD and NC-CHD were 50\%:50\% and 47.5\%:52.5\% respectively. There were a small number of the subject with history of low birth CHD. The subjects with the history of born with prematurity only found in NC-CHD group (12.5\%). Majority of family income were moderate to very high, C-CHD 69.2\%, and NC-CHD 70\%. There was no significant difference in family income between 2 groups. Pulmonary hypertension found 
Table 1. The Characteristics of Subject

\begin{tabular}{lccc}
\hline \multicolumn{1}{c}{ Variable } & C-CHD & NC-CHD(\%) & p \\
\hline Sex & & & \\
$\quad$ Male & $13(50.0)$ & $19(47.5)$ & 1.00 \\
$\quad$ Female & $13(50.0)$ & $21(52.5)$ & \\
Birth weight & & & \\
$\quad<2500 \mathrm{~g}$ & $1(3.8)$ & $3(7.5)$ & \\
$2500-4000 \mathrm{~g}$ & $25(96.2)$ & $37(92.5)$ & 0.48 \\
$>4000 \mathrm{~g}$ & $0(0.0)$ & $0(0.0)$ & \\
Prematurity & & & \\
$\quad$ Yes & $0(0.0)$ & $5(12.5)$ & 0.14 \\
$\quad$ No & $26(100.0)$ & $35(87.5)$ & \\
Family income & & & \\
$\quad$ Low income & $8(30.8)$ & $12(30.0)$ & 1.00 \\
$\quad$ Moderate-high & $18(69.2)$ & $28(70.0)$ & \\
Pulmonary hypertension & & \\
$\quad$ Yes & $1(3.8)$ & $2(5.0)$ & 1.00 \\
$\quad$ No & $25(6.2)$ & $38(95.0)$ & \\
\hline
\end{tabular}

Table 2. The Diagnosis of Congenital Heart

\begin{tabular}{|c|c|}
\hline Diagnosis & $\begin{array}{c}\mathbf{n} \\
(\%)\end{array}$ \\
\hline \multicolumn{2}{|l|}{ Cyanotic } \\
\hline Single ventricle & $2(2.8)$ \\
\hline Dounle outlet left ventricle & $1(1.4)$ \\
\hline Double outlet right ventricle & $2(2.8)$ \\
\hline Critical pulmonary stenosis & $1(1.4)$ \\
\hline Supracardiac TAPVD & $1(1.4)$ \\
\hline Tricuspid atresia & $1(1.4)$ \\
\hline Tetralogy of Fallot & $15(21.4)$ \\
\hline \multicolumn{2}{|l|}{ Non cyanotic } \\
\hline Atrial septal defect & $13(14.3)$ \\
\hline Patent ductus arteriosus & $9(11.4)$ \\
\hline Ventricular septal defect & $21(28.6)$ \\
\hline
\end{tabular}

Note: TAPVD=Totul Anomalous Pulmonary Veins drainage

only $3.8 \%$ in C-CHD group and $5 \%$ in NC-CHD group.

Tetralogy of Fallot was the predominant in C-CHD group $(21,4 \%)$ while VSD was the predominant in $\mathrm{NC}-\mathrm{CHD}$ group $(28,6 \%)$ as seen in table 2. Nutritional status of the subjects between groups were described in Table 3. The characteristic of subjects in this study were comparable between C-CHD and NC-CHD. This study found most subjects were age 27 months, similar to the study conducted in Jakarta with most subjects in the age range from 0.49 to 24 months, likewise a study conducted in Turkey
Table 3. Nutritonal status of C-CHD and NC-CHD

\begin{tabular}{|c|c|c|c|}
\hline Variable & $\begin{array}{c}n \\
(\%)\end{array}$ & $\begin{array}{c}n \\
(\%)\end{array}$ & $\mathbf{p}$ \\
\hline \multicolumn{4}{|l|}{ Weight-for-Age (W/A) } \\
\hline Severe under-nutrition & $11(42.3)$ & $17(42.5)$ & \multirow{4}{*}{0.80} \\
\hline $\begin{array}{l}\text { Moderate-severe } \\
\text { undernutrition }\end{array}$ & $9(34.6)$ & $10(25)$. & \\
\hline Normal & $6(23.1)$ & $12(30.0)$ & \\
\hline Overweight & $0(0.0)$ & $1(2.5)$ & \\
\hline \multicolumn{4}{|l|}{ Lenght-for-Age (L/A) } \\
\hline Severe stunting & $7(26.9)$ & $14(35.0)$ & \multirow{3}{*}{0.98} \\
\hline Stunting & $7(26.9)$ & $7(17.5)$ & \\
\hline Normal & $12(46.2)$ & $19(38.0)$ & \\
\hline \multicolumn{4}{|l|}{ Weight-for-Length (W/L) } \\
\hline Severe under-nutrition & $11(42.3)$ & $9(22.5)$ & \multirow{4}{*}{0.54} \\
\hline $\begin{array}{l}\text { Moderate-severe } \\
\text { undernutrition }\end{array}$ & $2(7.7)$ & $13(32.5)$ & \\
\hline Normal & $12(46.2)$ & $17(42.5)$ & \\
\hline Overwright & $1(3.8)$ & $1(2.5)$ & \\
\hline \multicolumn{4}{|c|}{ Head Circumference-for-Age (HC/A) } \\
\hline Microcephaly & $8(30.7)$ & $20(50.0)$ & \multirow[t]{2}{*}{0.29} \\
\hline Normocephaly & $18(69.2)$ & $20(50.0)$ & \\
\hline \multicolumn{4}{|c|}{ Mid Upper Arm Circumference-for-Age (MUAC/A) } \\
\hline Severe under-nutrition & $8(30.8)$ & $11(27.5)$ & \multirow{4}{*}{0.80} \\
\hline $\begin{array}{l}\text { Moderate-severe } \\
\text { undernutrition }\end{array}$ & $7(26.9)$ & $13(32.5)$ & \\
\hline Normal & $11(42.3)$ & $16(40.0)$ & \\
\hline Overweight & $0(0.0)$ & $0(0.0)$ & \\
\hline \multicolumn{4}{|c|}{ Skinfold Thickness-for-Age (SFT/A) } \\
\hline Severe under-nutrition & $4(15.4)$ & $2(5.0)$ & \multirow{4}{*}{0.53} \\
\hline $\begin{array}{l}\text { Moderate-severe } \\
\text { undernutrition }\end{array}$ & $2(7.7)$ & $5(12.5)$ & \\
\hline Normal & $20(76.9)$ & $33(80.0)$ & \\
\hline Overweight & $0(0.0)$ & $0(0.0)$ & \\
\hline
\end{tabular}

(Sjarif et al., 2011; Arodiwe et al., 2015). Age is an important factor for CHD natural history that would affect the progression of complications of CHD. There were no significant difference in sex distribution, history of birth weight,history of prematurity, family income and the presence of pulmonary hypertension. Study in Thailand found no significant difference sex distribution in C-CHD and NC-CHD with malnutrition (Ratanachu, 2011). Choudhury (2018) in Bangladesh also found no significant difference in sex distribution children with cyanotic and acyanotic CHD. Low birth weight and prematurity are the important risk factors for the occurence of nutritional disorder (Arodiwe et al., 2015). Malnutrition in children 
is one of the global health problems, most in poor family. Low family income or poverty is the important factor resposible for poor health and nutritional status (Arora et al., 2014). Most of the patients of cyanotic and acyanotic CHD in Bangladesh belonged to midle class socioeconomic status, and no significant difference between the groups (Choudhury, 2018). The presence of pulmonary hypertension is the important factor to malnutrition and growth failure in children with CHD. Pulmonary hypertension had impact on growth and nutrition, both in cyanotic and acyanotic CHD. Patients with cyanotic and pulmonary hypertension were more affected than patients with acyanotic and pulmonary hypertension (Arodiwe, 2015). Cyanotic patients without pulmonary hypertension and acyanotic patients with pulmonary hypertension had significantly lower weight, height, and head circumference compared to CHD children. Compared to acyanotic patient without pulmonary hypertension, weight and head circumference in acyanotic patients with pulmonary hypertension were significantly lower (Noori et al., 2017).

Tetralogy of Fallot was the predominant in C-CHD group (21.4\%) while VSD was the predominant in NC-CHD group (28.6\%). The same result with our study, the common type of C-CHD and NC-CHD in Bangladesh were Tetralogy of Fallot (63.3\%) and VSD (53.3\%) respectively but the prevalence were higher (Choudhury, 2018). This showed that there was differences in distribution of the kind of CHD between countries.

Undernutrition is common in chidren with CHD. We found C-CHD (42.3\%) and NC-CHD $(42.5 \%)$ with severe undernutrition. C-CHD (34.6\%) and NC-CHD (25\%) with moderate to severe undernutrition while overweight found only in $1.5 \%$ subjects. The prevalence were higher if compared to result of study by Ratanachu (2011) in Thailand. Which found 53\% malnutrition, consist of $3 \%$ overweight, $28 \%$ under nutrition, $22 \%$ wasting and $16 \%$ with stunting condition, in children with CHD. In our study we found more children with CHD suffered from undernutrition. Many factors can cause the nutritional disorder in children with CHD. Hemodynamic factors, low growth potential as low birth weight, small gestational age, lower parental anthropometric, and accompanied by other congenital abnormalities are the important predictor for the occurrence of nutritional disorders (Arodiwe et al, 2015). Other risk factors are prematurity and genetic abnormalities or disorders beyond the heart may affect energy intake, gastrointestinal absorption, energy expenditure, and growth expectations are affected by genetic condition like Turner's or Down syndrome (Nydegger and Bines, 2006). Infant with complex CHD suffered from failure to grow is well documented include presence of associated chromosomal abnormalities, cyanosis, and cardiac failure adds to the complexity and challenge. The etiology of malnutrition etiology can be grouped into: inadequate intake, inefficient absorption and utilization, and/or increased energy needs (Rodica 2013). The difference growth disorders in patients with CHD compared with healthy children can be attributed to differences in the factors, including gender, age, cardiac abnormalities, simultaneous multiple congenital heart defects, and congestive heart failure (Noori et al., 2017). Study in Iran have found that cytokines have a strong effect on feeding, growth, weight, and energy intake in patients with CHD (Noori et al., 2016).

Anthropometric Z-score profiles both in C-CHD and NC-CHD in this study statistically found no significant differences in the impairment of nutritional status. This is influenced by various factors, including hemodynamic disturbances associated with cardiac physiological and degree of severity of the disease, inadequate food intake, malabsorption gastrointestinal, neurological disorders, increased energy expenditure, coupled with fluid loss as much as $10-15 \%$ compared with normal children because of circumstances tachypneu, less fluid, intake and the use of diuretics. C-CHD makes hypoxic hypoxia condition that lead to anorexia with concomitant decrease in body weight (De Onis et al., 2009). This result come from both congestive heart failure and lack of oxygen. Heart failure, fluid and sodium overload, and cardiac haemodynamics disturb in NC-CHD lead to worsening heart failure and decreased intake and make inadequate individual overall nutrient intake. Anorexia will accompany with malnutrition and endangers the condition. 
Dyspnea and tachypnea cause a tendency towards faster fatigue and decreasing intake. Growth is affected by chronic hypoxia.

Stunting found in $53,0 \%$ in both group. Stunting found more in NC-CHD than in C-CHD ( $31,8 \%$ vs $21,2 \%)$. A study found $66,67 \%$ children suffered from stunting in C-CHD children and $62,68 \%$ with stunting in NC-CHD children and there were no difference between groups (Harikrishnan \& Handrasekharan, 2009). The exact cause of stunting in C-CHD children is not well explained yet. This may be cause by chronic cyanosis cause chronic malnutrition. Chronic hypoxia in CHD provide direct and indirect effects on reduced serum hormone Insulin like growth factor I (IGF-I) cause impaired of bone center and eventually impaired nutritional status and stunted growth. Delays bone growth will lead to below normal body length. Children with CHD have a body length under normal than their age.

Microcephaly found more in NC-CHD than in C-CHD children (50\% vs $30.7 \%$ ) but sstatistically no significant difference between groups. Children with CHD will experience widespread neurodevelopmental disorders. Microstructural brain abnormalities and metabolic disorders occur after birth due to insufficient of oxygen and delivery of essential substances in the brain. Abnormal brain growth is more common in infants with C-CHD compared with NC-CHD. In C-CHD, $30-40 \%$ of systemic blood back to the left heart without flowing into pulmonary circulation, causing systemic oxygen decline that eventually affects all organs including the brain. A reduction in systemic blood flow and brain blood flow cause abnormal growth of the brain (Raheem \& Mohamed, 2012).

Nutritional status measurement based on circumference of upper arm found in C-CHD children were very thin and not significantly different with NC-CHD children. Nutritional status measurement based on skin fold thickness increased in line with increased high-calorie intake or low-energy expenditure. Evaluation of nutritional status by skin fold thicknes in children from a population with a low fat content would not sensitive. Decrease in muscle mass can be seen in levels of creatinine and limb muscle mass measurement than using weight (White et al., 2005). Measurement of muscle mass is a compensatory mechanism for the provision of amino acid gluconeogenesis and protein synthesis in liver.

Limitation of this study were this study have not included children without CHD which match age and sex as control subjects, and no laboratory examination to support this study.

\section{CONCLUSION}

Conclusion of this study was antropometric profiles of children with cyanotic congenital heart disease were statistically no significant difference with non cyanotic congenital heart disease.

\section{REFERENCES}

Arodiwe, I., Chinawa, J., Ujunwa, F., Adiele, D., Ukoha, M., \& Obidike, E. (2015). Nutritional status of congenital heart disease (CHD) patients: Burden and determinant of malnutrition at university of Nigeria teaching hospital Ituku - Ozalla, Enugu. Pak J Med Sci, 31(5): 11401145. doi: 10.12669/pjms.315.6837.

Arora, D., Datta, S., \& Sau, S., K. (2014). An assessment of socio-economic factors on nutritional status in primary school - A cross sectional study in Purulia of West Bengal. International Journal of occupational safety and health, 4(2):15-18. doi: 10.3126/ijosh. v4i2.14665

Chowdhury, F., Hoque, M., Ali, M. M., \& Hossain, M. A. (2018). Comparison of growth in children with cyanotic and acyanotic congenital heart disease in tertiary care hospital. Journal of Bangladesh College of Physicians and Surgeons, 36(2)64-69. doi: 10.3329/jbcps.v36i2.36068

Daymont, C., Neal, A., Prosnitz, A., \& Cohen, M. S. (2013). Growth in children with congenital heart disease. Pediatrics, 131(1), 236-42. doi: 10.1542/peds.2012-1157

De Onis, M., Onyango, A.W., Borghi, E., Garza, C., \& Yang, H. (2009a). Comparison of the world health organization (WHO) child growth standards and the national center for health statistics/WHO international growth reference: implications for child health programmes. Public Health Nutr, 9(7), 942-7. Retrieved from https:// www.ncbi.nlm.nih.gov/pubmed/17010261

Hassan, B. A., Albanna, E. A.,Morsy S. M., Siam A.G., Al Shafie, M. M., Elsaadany, H. 
F., Sherbiny, H. S., \& Grollmuss, O. (2015). Nutritional status in children with unoperated congenital heart disease: an Egyptian center experience. Front. Pediatr, 15 June 2015 Retrieved from https://doi.org/10.3389/ fped.2015.00053

Harikrishnan, S., \& Handrasekharan, C. K. (2009). Pulmonaryhypertension. PVRI Review 1,13-9. Retrieved from http://www.pvrireview.org/ article.asp?issn=0974-6013 Accessed May 2012.

Kumar, R. K., \& Tynan, M. J. (2005). Catheter interventions for congenital heart disease in third world countries. Pediatric cardiology, 26(3), 1-9. Retrieved from https://www.ncbi. nlm.nih.gov/pubmed/16082576

Noori, N., M., Moghaddam, M. N., Teimouri, A., Boryri, T., \& Abadi, S., H. (2017). Evaluation of growth statur in children with congenital heart disease: A case control study. Int J Pediatr, 5(12), 6503-14.

Noori, N. M., Moghaddam, M. N., Teimouri, A., Shahramian, I., \& Keyvani, B. (2016). Evaluation of serum level of tumor necrosis factor-alpha and interleukin-6 in patients with congenital heart disease. Niger Med J. 57(4), 233-237. doi: 10.4103/0300-1652.188353.
Nydegger, A., \& Bines, J. E. (2006). Energy metabolism in infants with congenital heart disease. Nutrition, 22(7-8), 697-704. Retrieved from https://www.ncbi.nlm.nih.gov/ pubmed/16815484

Raheem, M. M. A., \& Mohamed, W.A. (2012). Impact of congenital heart disease on brain development in newborn infants. Annals of pediatric cardiology, 5(1), 21-6. doi: 10.4103/0974-2069.93705

Ratanachu-Ek, S., \& Pongdara, A. (2011). Nutritional status of pediatric patients with congenital heart disease: pre- and post cardiac surgery. J Med Assoc Thai. 94: Suppl 3:S133-7. Retrieved from https://www.ncbi.nlm.nih.gov/ pubmed/22043766

Rodica, T. (2013). Nutritional approach of Pediatric patients diagnosed with congenital heart disease. Acta Medica Merisiensis, 59(2), 121-125. doi: 10.2478/amma-2013-0029

Rubia, B., \& Kher, A. (2018). Anthropometric assessment in children with congenital heart disease. Int J Pediatr, 5(2),634-639. Retrieved from https://www.ijpediatrics.com/index.php/ ijcp/article/view/1310 